\title{
Cartographic modeling of the temperature fields of the land fund of the Novosibirsk region using satellite data of the MODIS/Terra spectroradiometer
}

\author{
Polina V. Voronina ${ }^{1,2}$, Elena A. Mamash ${ }^{1}$, Igor A. Pestunov ${ }^{1}$, \\ Svetlana Ya. Kudryashova ${ }^{3}$ and Aleksandr S. Chumbaev ${ }^{3}$ \\ ${ }^{1}$ Federal Research Center for Information and Computational Technologies, Novosibirsk, Russia \\ ${ }^{2}$ Novosibirsk State University, Novosibirsk, Russia \\ ${ }^{3}$ Institute of Soil Science and Agrochemistry of SB RAS, Novosibirsk, Russia
}

\begin{abstract}
The results of cartographic modeling of the temperature fields of soils of the land fund of the Novosibirsk region using satellite data obtained by the MODIS/Terra spectroradiometer are considered. The developed cartographic models give a clear idea of the spatial structure of the temperature fields of the soil cover of the Novosibirsk region and the qualitative changes in the temperature regime of soils in different years. According to the data of daytime and nighttime surveys, the peculiarities of the temperature distribution of the soil cover for 2001 and 2010 were established. The values of the average annual temperature of the underlying surface for 2001-2014 were calculated. It is assumed that thermal resources not reflected in the generalization of zonal zoning can be identified on cartographic models. These resources have independent ecological significance and characterize the diversity of landscape, anthropogenic and other types of climate.
\end{abstract}

\section{Keywords}

MODIS, satellite data processing, soil surface temperature, cartographic modeling of soil temperature fields, land fund of the Novosibirsk region.

\section{Introduction}

Rational use of the land fund of a territory is impossible without construction of cartographic models for land surface temperature fields. The analysis of such models allows distinguishing the climatic features of the regional soil climate, revealing the uniqueness of the soil climate, and indicating their possible value for agricultural and industrial purposes [1, 2, 3, 4]. While studying the soil temperature fields the data of space imagery in the thermal infrared range can be used as a source of information [5, 6, 7]. Such images data can be obtained with the MODIS spectroradiometer installed on the Terra satellite. The regularity of the survey and the significant coverage (sometimes very inaccessible) territory is the undoubted advantage of using remote sensing (RS) data of low spatial resolution [8, 9]. For a wide scale natural-anthropogenic complex (such as the Novosibirsk region) the assessment of land fund heat supply promotes efficiency of the using of all categories of land, regardless of the intended purpose, and its

SDM-2021: All-Russian conference, August 24-27, 2021, Novosibirsk, Russia

$\bigoplus$ pestunov@ict.sbras.ru (I. A. Pestunov)

(c) (1) $\odot 2021$ Copyright for this paper by its authors. Use permitted under Creative Commons License Attribution 4.0 International (CC BY 4.0).

[eEUR Workshop Proceedings (CEUR-WS.org) 
temperature regime is a tool in the study of the ecological state of the territory and a rational use of its natural resources $[10,11,12,13,14]$.

Cartographic modelling of the temperature fields of the land surface of the Novosibirsk region by MODIS/Terra satellite data for studying the temperature regime of soils and identifying its features is the purpose of this work. To achieve this goal, the analysis of the spatio-temporal series of temperatures obtained by processing and aggregation of satellite images for various time intervals was carried out. The average annual temperature of the land surface is a meteorological indicator. It reflects the most important physical processes occurring in atmosphere and soils. Thus, the average annual land surface temperature is an indicator of the characteristics of the soil climate and the interaction of two interpenetrating environments - soils and plants.

\section{Study area}

The Novosibirsk Region is located in the southeast of the West Siberian Plain $\left(55^{\circ} \mathrm{N}-85^{\circ} \mathrm{E}\right)$, occupies a relatively small and compact territory -177.8 th. $\mathrm{km}^{2}$, which length is $444 \mathrm{~km}$ from North to South and $642 \mathrm{~km}$ from East to West (Figure 1).

According to soil and climatic zoning [10], the Novosibirsk region is characterized by a wide range of zonal climate types, the thermal resources vary from $1200^{\circ} \mathrm{C}$ in the southern taiga zone to $2100{ }^{\circ} \mathrm{C}$ in the typical steppe zone. The region includes several zones with landscape climate types: the southern taiga on meadow-boggy; subtaiga on gray forest soils; northern foreststeppe on chernozems leached and meadow solonetzic; southern forest-steppe on chernozems

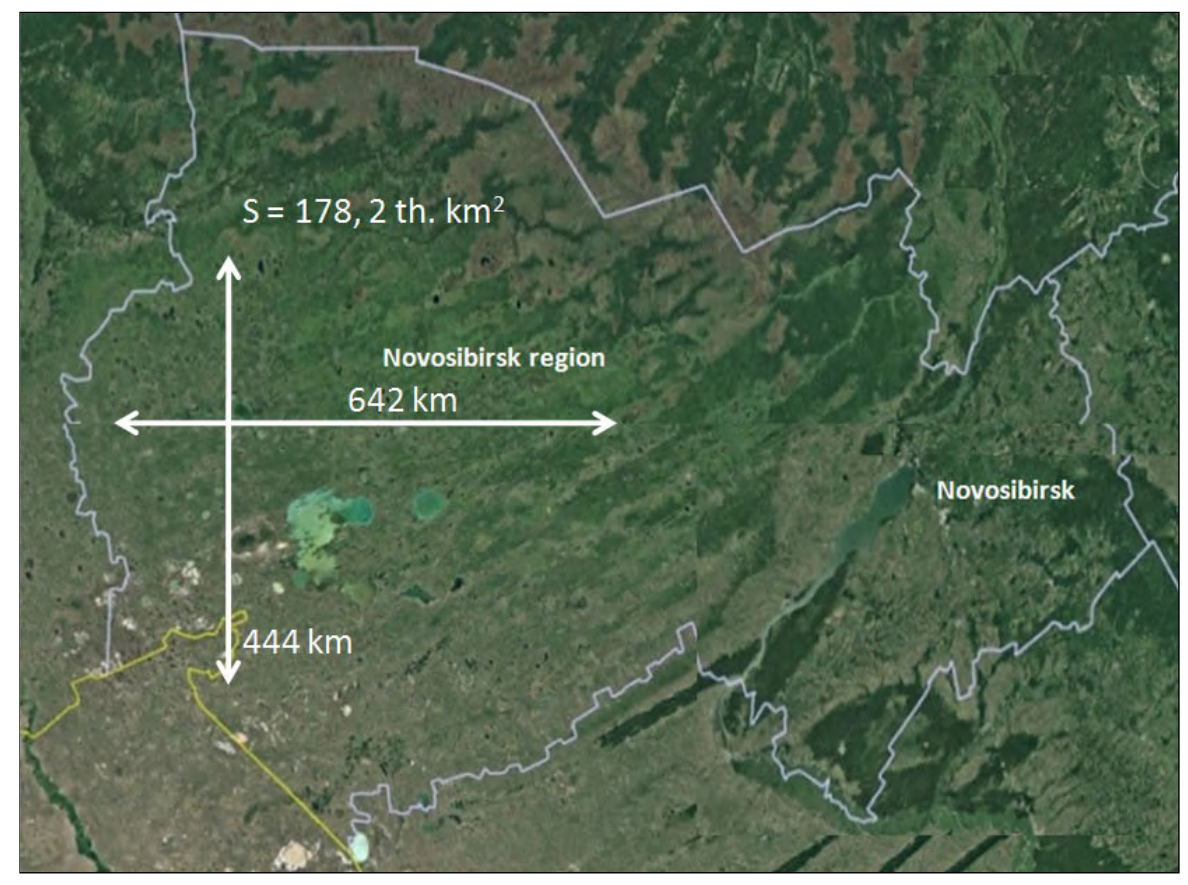

Figure 1: Google Earth Pro image of the research area (Novosibirsk region). 
ordinary and leached and meadow-alkaline soils; steppes on solonetzic southern and ordinary chernozems and on sod-podzolic; and steppes on gray forest soils in Salair vertical zonation system.

The forest-steppe subzone of the Novosibirsk region includes Barabinsky, Priobsky and Salairsky climatic districts. The vast Barabinsk forest-steppe $\left(117\right.$ th. $\left.\mathrm{km}^{2}\right)$ is located within a wide strip of the Ob-Irtysh interfluve and is a plain slightly inclined from northeast to southwest, slightly elevated above sea level. The relief of Baraba is hilly in the north and hryvnia or hryvniahollow in the south. Its characteristic geomorphological features are boggy inter-crest basins, many fresh and salt lakes, a high degree of frostiness and swampiness in the north, which sharply decreases in the south $[10,11,12,13]$. Zonal climates of Baraba are divided into a system of local climates united in the Northern, Western, Central and Eastern regions. It's climateforming factors affects geographical distribution and heat supply of the of soils. Podzolic, gray forest soils and ordinary chernozems are widespread in the northern and northeastern parts of Baraba. The western and southwestern regions of the Barabinsk lowland are characterized by ordinary and solonetzic chernozems, solodized soils and malts. The center of the Baraba is occupied by meadow chernozems. The flat nature of a relief with almost ideal latitudinal bioclimatic zoning makes the Baraba forest-steppe a unique object of research on a planet. This makes the research region promising for understanding the dynamics of changes in the zoning of ecosystems in a changing climate.

The Novosibirsk city (located on the Ob river) is the center of a large agglomeration, representing a compact accumulation of settlements, mainly urban, locally intertwining and united in a complex multicomponent dynamic system with intensive production, transport and cultural links. The core of the agglomeration is formed by the city of Novosibirsk and adjacent towns and villages. A characteristic feature of the Novosibirsk urban agglomeration is its pronounced monocentricity, since the city occupies an area much larger than the total area of its constituent settlements. The developing urban agglomeration has a powerful impact on environmental objects including the cause of the formation of heat islands which lead to a change in the temperature regime of urbanized territories. Thus, the Novosibirsk region is a complex natural and anthropogenic complex, and its temperature regime is a tool for the study of the ecological state of the territory [14].

\section{Research materials - spatio-temporal data series}

One of the features of this study is the extraction and processing of satellite RS data from the archive of the Federal Research Center of ICT (FRC ICT) using the hVault technology [16]. Unlike traditional unloading of individual scenes with subsequent connection to a geographic information system (which allows visualizing data as a set of thematic layers but complicates simultaneously using a large number of images with complex processing functions), hVault technology provides virtual integration of the data from the archive into relational DBMS. This technology is based on the principle of data presentation as a set of tables containing satellite image data or derived information products, followed by analysis of spatio-temporal series by means of a DBMS. The mapping of these data to tables is as follows. Each spatial point is associated with a cortege containing geographic coordinates, a time interval of observations, and 
a sequence of measured values. In this form, data extraction and transformation are performed using SQL queries. The original data storage format and their division into separate files have no matter to the user. The software module implementing this principle was developed as an extension of the free PostgreSQL DBMS [15].

In the analysis of the spatio-temporal series of the remote sensing data, the products obtained as a result of processing MODIS/Terra data were used. The temperature values are reconstructed from measurements of the intensity of infrared radiation recorded in channels $31(10.78-11.28 \mu \mathrm{m})$ and $32(11.77-12.27 \mu \mathrm{m})$, according to the MOD11A1 product construction algorithm [15]. The data contained in MOD11A1 are presented on a regular grid in a sinusoidal projection with a cell size of $\sim 1 \mathrm{~km}$. Under good (cloudless) atmospheric observation conditions, the algorithm [16] provides an accuracy of surface temperature recovery within $1 \mathrm{~K}$.

The average values of the temperature measured at nighttime and daytime, as well as their difference at a point, were calculated by data from the FIC ICT archive for

- the whole year (2002 and 2010);

- for the entire time interval 2001-2014 (a period of 14 years);

- the spring period from April 10 to May 30 for each calendar year from 2001 to 2014;

- the spring period from April 10 to May 30 for the entire time interval 2001-2014 (a period of 14 years).

The average value at a point for 14 years was calculated by average annual arrays to speed up the calculations. The study area covers 400000 points. It can be said with some convention that the calculation with the hVault technology is equivalent to simultaneous processing of 365 satellite images.

\section{Results and discussion}

The average annual temperature of the soil surface is a meteorological element which reflects the characteristics of heat exchange throughout the year and depends on the intensity of solar radiation, the characteristics of atmospheric circulation, and the physical characteristics of the soil cover. To get an idea of the changes in the temperature regime of the Novosibirsk region we obtain the averaged surface temperature at the geographical point of the territory for a calendar year and for all the years under consideration (from 2001 to 2014) (Figure 2).

According to the nighttime survey, the lowest minimum average temperature was in 2010 and 2012, and the highest maximum was in 2002 and slightly lower in 2003. According to the daytime survey, the lowest average temperature was in 2010, and the highest - in 2010 and 2012. According to the data of the regime network of the Hydrometeorological Service, the average annual soil temperature on the surface changes by $1-2{ }^{\circ} \mathrm{C}$, and at the same time, zoning is strictly traced: $0{ }^{\circ} \mathrm{C}$ - in the subtaiga; $1{ }^{\circ} \mathrm{C}$ - in the forest-steppe; and $2{ }^{\circ} \mathrm{C}$ - in the steppe. It is noted that the surface temperatures of saline soils are $1^{\circ} \mathrm{C}$ lower than on non-saline automorphic soils.

Extracted spatio-temporal series of the Earth surface temperature were used for calculation of the average values for nighttime and daytime surveys at a geographic point and its differences for one calendar year. Calculations were carried out for each year from 2001 to 2014. The 


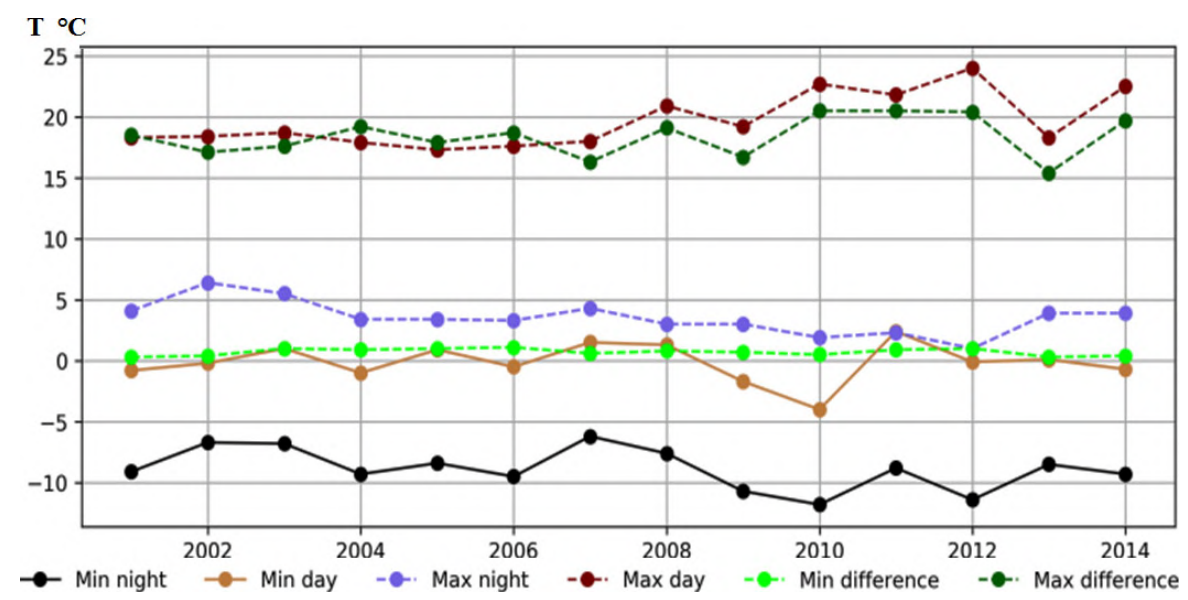

Figure 2: Average values and difference of soil surface temperature according to data of nighttime and daytime surveys.

obtained results allow suggesting the heterogeneity of the spatial structure of Earth surface temperature and qualitative changes in the temperature regime from year to year. Figures 3 and 4 shows the distribution of the average temperature according to the data of nighttime and daytime surveys and its differences for 2002 and 2010, respectively. It can be seen that the average temperatures differ significantly in these years, the land surface temperature in 2002 is higher than in 2010. Both in the more severe and in the milder manifestation of the weather regime, the classic latitudinal zoning of the land surface temperature distribution is clearly visible. It is very typical for the southeast of Western Siberia: from north to south by zones, there is a stable increase in average negative, average long-term minimum temperatures and absolute minimum temperatures. Thus, the severity of the winter period increases from south to north, which also causes an increase in the environmental load on human and animal organisms during winter periods.

Figure 5 shows the distribution of the average annual temperature of the soil surface in the system of zonal types of climate in the Novosibirsk region. First, the average value of the temperature in a pixel was determined from the data for one calendar year for 2001-2014. Then the average value for 2001-2014 was found based on the RS data for nighttime and daytime surveys. The same actions were performed for the difference between the daytime and nighttime temperatures of the underlying surface. The latitudinal zoning of the soil temperature distribution from south to north from the typical steppe zone to the southern taiga zone is clearly traced here (Figure 5, $a$ and $b$ ). Within the zonal subdivisions, subzonal types of soil climates of the Baraba lowland can also be distinguished - podzolic and gray forest soils are widespread in the northern part, meadow chernozems soils occupy its central part, and leached and ordinary chernozems prevail in the southern subzone of the forest-steppe. Temperature fields with similar temperature values, marked on the map of the region, can characterize a variety of landscape, anthropogenic and other types of climate. Thermal resources not reflected in the generalization of zonal zoning are noted. These resources have independent ecological significance and can be identified on cartographic models. The average difference between day 


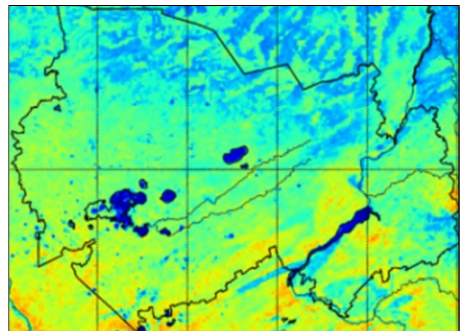

$a$

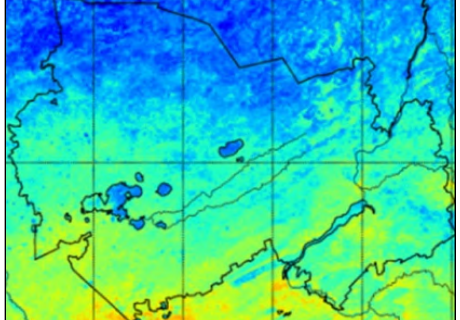

$b$

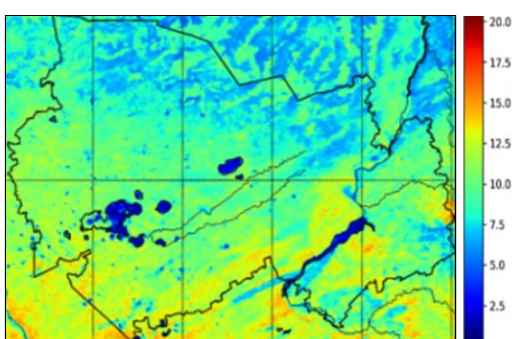

C

Figure 3: Distribution of the average temperature for 2002. Nighttime (a), daytime survey data (b), and the difference between daytime and nighttime data $(c)$.

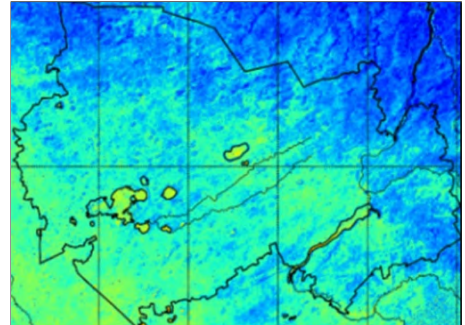

$a$

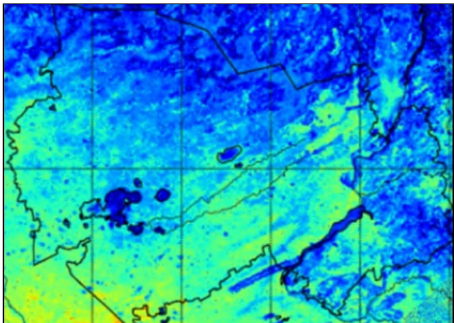

$b$

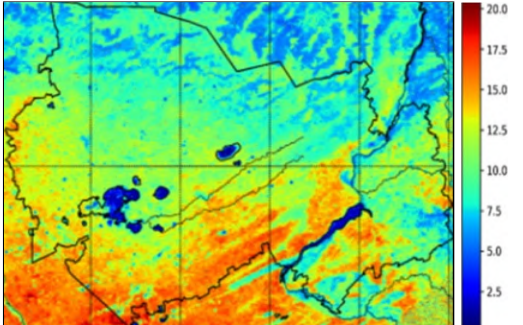

Figure 4: Distribution of the average temperature for 2010. Nighttime (a), daytime survey data $(b)$, and the difference between daytime and nighttime data $(c)$.

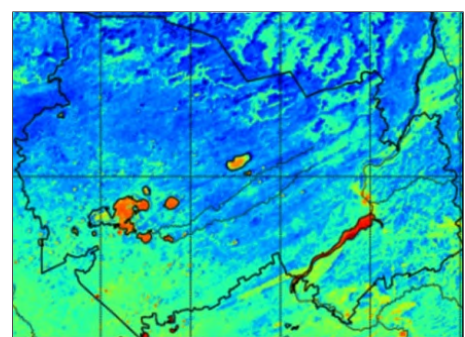

$a$

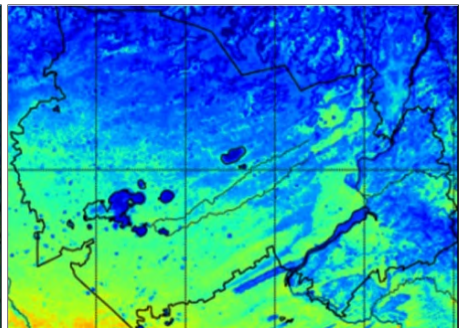

$b$

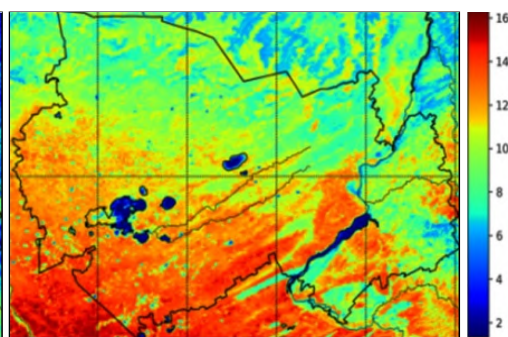

Figure 5: Distribution of the average annual temperature of the underlying surface of the Novosibirsk region for the period 2001-2014. Nighttime survey data (a), daytime survey data $(b)$, and the difference between daytime and nighttime data $(c)$.

and night temperatures varies from high in the south of the region to lower in the north, again with a clearly pronounced latitudinal zoning (Figure $5, c$ ).

Soil temperature is influenced by the type of soil, the nature of its salinization, and granulometric composition. Thus, the average annual temperature of the underlying surface throughout the entire territory of the Novosibirsk region varies from 0 to $2{ }^{\circ} \mathrm{C}$. The annual temperatures of automorphic and semi-hydromorphic soils are positive; its variability across the territory is $1.8-2.3{ }^{\circ} \mathrm{C}$. Saline soils are, on average, colder than non-saline soils per year. The pronounced seasonal rhythm of all components of nature in the temperate zone of the Novosibirsk region is located. It determines both the seasonal variation of soil temperature and the originality of the 
factors of climate formation, which is reflected in the specificity of the thermal regime of soils. The dates of the transition through zero temperature are taken as the beginning of warm and cold periods in the soil, in the first case from negative ones, in the other - from positive ones. Figure 6 shows graphs of changes in the average day and night temperatures for the region for 2002 and 2010. Note that the transition from negative daily mean values to positive ones occurs in April (in rare, anomalous years in March) and nighttime temperatures change sign in April. Although, as we can see from the charts, negative values also occur in May.

A steady transition from negative to positive temperatures marks the beginning of a warm period. It is important for agricultural land use. However, it is not possible to carry out a study to establish the day when both nighttime and daytime surface temperatures become positive in all or part of the region, due to significant gaps in the analyzed spatio-temporal data series (both in space and in time). Nevertheless, we made an attempt to obtain the distribution of soil temperature at the assumed dates of the spring seasonal change in the sign of the temperature value.

The great importance for the use of land in agricultural are the timing of the transition of night and day temperatures through the zero mark. Figure 7 shows the results of the analysis of the spring change in the mean temperature values near the days of the change in the temperature sign.

Three monthly periods were considered: from April 10 to May 10, 2010; from April 20 to May 20, 2010; and from May 1 to May 30, 2010. For each period, the average night and day temperatures in a pixel and its differences were obtained. Average daily temperatures in these time intervals become positive almost throughout the entire territory, moreover, they significantly exceed $10{ }^{\circ} \mathrm{C}$, and we do not present them. But the average night temperatures in the pixel are still negative, but comparing the three spring periods, it can be seen that the "warming" of the soil surface occurs in the latitudinal-zonal direction. In May, almost the entire territory of the Novosibirsk Region is already in the zone of positive night temperatures (Figure 7, c).

In May, the soil surface temperature fluctuates more significantly than in winter. It is clearly seen in Figure 8.
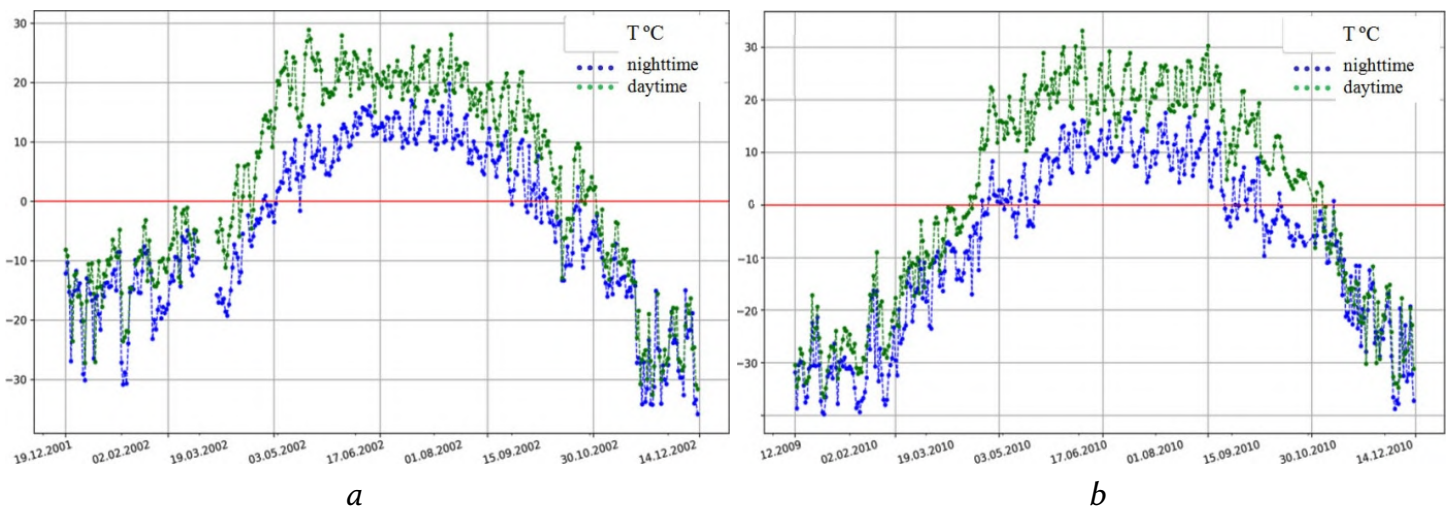

Figure 6: Average temperature $\left({ }^{\circ} \mathrm{C}\right)$ in the Novosibirsk region for $2002(a)$ and $2010(b)$. 


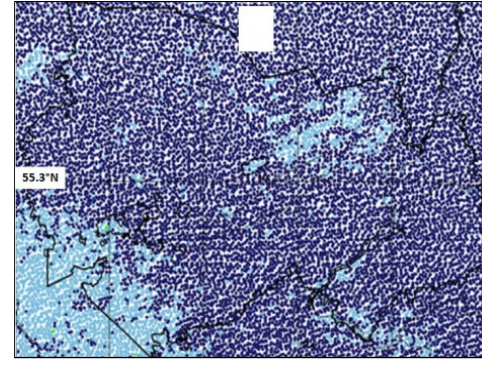

$a$

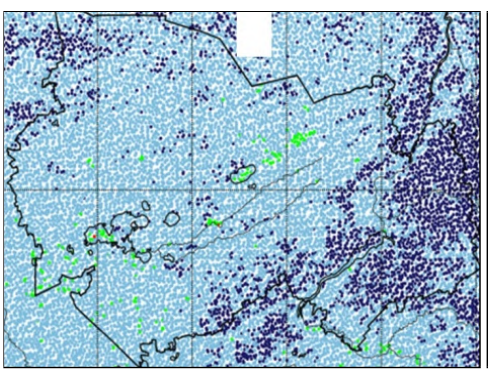

$b$

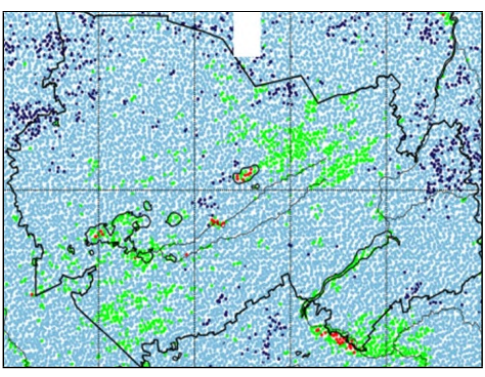

$c$

Figure 7: Distribution of average night temperature for periods: $a-10.04-10.05 .2010 ; b-20.04-$ 20.05.2010; $c-1.05-30.05 .2010$. Correspondence of colors to temperature values, $T^{\circ} \mathrm{C}$ : dark blue $-<0$; light blue $-0-5$; green $-5-10$; red $->10$.

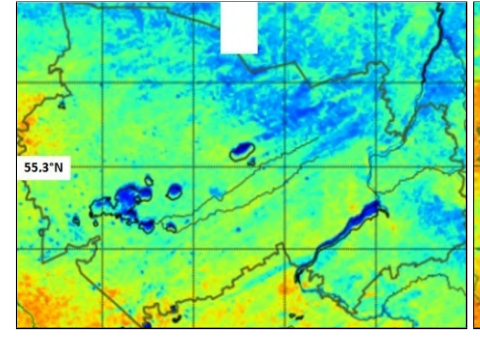

$a$

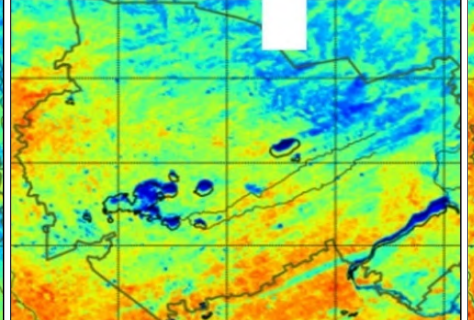

$b$

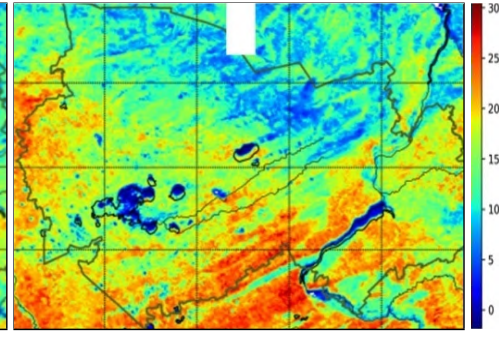

Figure 8: Distribution of the average difference between day and night temperatures for the periods: $a-10.04-10.05 .2010 ; b-20.04-20.05 .2010 ; c-1.05-30.05 .2010$.

The soil temperature in the northern regions passes to positive values faster and more intensively than in the regions located to the south. As you can see, zoning is well traced here.

\section{Conclusion}

Soil surface temperature is an important indicator in assessing disturbances in ecological and climatic interactions. Cartographic models of thermal resources obtained from the analysis of the spatio-temporal series of Terra/MODIS satellite data allows assessing the heat supply of the land fund of the Novosibirsk region, which makes it possible to effectively use all categories of land, regardless of their intended purpose.

Studying the temperature of the soil surface also makes it possible to reveal the features of the soil climate, which is important for considering ecological processes and their interaction with two interdependent environments - soil cover and vegetation. It also requires an analysis of the spatio-temporal series of the underlying surface temperature.

The obtained results can serve as a basis for zoning the territory of the Novosibirsk region according to the degree of environmental safety. 


\section{Acknowledgments}

The study was carried out according to the state assignment of Federal Research Center for Information and Computational Technologies and Institute of Soil Science and Agrochemistry of Siberian Branch of the Russian Academy of Sciences with financial support from the Ministry of Science and Higher Education of the Russian Federation.

\section{References}

[1] Kudryashova S.Ya., Chumbaev A.S., Pestunov I.A., Sinyavskiy Yu.N., Chubarov D.L., Bezborodova A.N., Ermakov N.B. Cartographic modeling of soil temperature fields for Middle Siberia Transect based on conjoint analysis of automated ground-based and satellite temperature data // CEUR Workshop Proceedings. 2020. Vol. 2534. P. 124-131. ISSN:16130073. Available at: http://ceur-ws.org/Vol-2534/21_short_paper.pdf.

[2] Voronina P.V., Chubarov D.L., Dobretsov N.N. Analysis of time series of the Earth's surface temperature // Proceedings of the International Conference "Computational Mathematics and Mathematical Geophysics" dedicated to the 90th anniversary of the birth of Academician A.S. Alekseev. 2018. P. 108-114. (In Russ.)

[3] Voronina P.V., Chubarov D.L., Dobretcov N.N. The study of the temperature regime of the Novosibirsk agglomeration according to the satellite sensing data // CEUR Workshop Proceedings. 2020. Vol. 2534. P. 327-333. ISSN:1613-0073. Available at: http://ceur-ws.org/ Vol-2534/55_short_paper.pdf.

[4] Voronina P.V., Chubarov D.L., Dobretsov N.N. Temperature anomalies on the territory of Barabinskaya Lowland. The first results // Interexpo Geo-Siberia. 2019. Vol. 4. No. 1. P. 28-36. (In Russ.)

[5] Voogt J.A., Oke T.R. Thermal remote sensing of urban climates // Remote Sensing of Environment. 2003. No. 86. P. 370-384.

[6] Weng $Q$. Thermal infrared remote sensing for urban climate and environmental studies: Methods, applications, and trends // ISPRS Journal of Photogrammetry and Remote Sensing. 2009. No. 64. P. 335-344.

[7] Weng Q., Quattrochi D.A. Thermal remote sensing of urban areas: An introduction to the special issue // Remote Sensing of Environment. 2006. No. 104. P. 119-122.

[8] Cheval S., Dumitrescu A. The July urban heat island of Bucharest as derived from MODIS images // Theoretical and Applied Climatology. 2009. No. 96. P. 145-153.

[9] Pu R., Gong P., Michishita R., Sasagawa T. Assessment of multi-resolution and multisensor data for urban surface temperature retrieval // Remote Sensing of Environment. 2006. No. 104. P. 211-225.

[10] Soil and climatic atlas of the Novosibirsk region. Novosibirsk: Nauka, Sib. Otdelenie, 1978. 121 p. (In Russ.)

[11] Voronina L.V., Gritsenko A.G. Climate and ecology of the Novosibirsk region. Novosibirsk: SGGA, 2011. 228 p. (In Russ.)

[12] Kravtsov V.M., Donukalova R.P. Geography of the Novosibirsk region. Novosibirsk: Infopress, 1999.205 p. (In Russ.) 
[13] West Siberian Lowland. Moscow: Geography, 1963. 262 p. (In Russ.)

[14] Shokin Yu.I., Pestunov I.A., Chubarov D.L., Kikhtenko V.A., Mamash E.A., Dobretsov N.N., Voronina P.V., Sinyavsky Yu.N. Information system for satellite data acquisition, archiving and analysis as an instrument for monitoring of objects of artificial and natural origin // CEUR Workshop Proceedings. 2020. Vol. 2534. P. 229-240. ISSN:1613-0073. Available at: http://ceur-ws.org/Vol-2534/39_short_paper.pdf.

[15] Shokin Yu.I., Dobretsov N.N., Mamash E.A., Kikhtenko V.A., Voronina P.V., Smirnov V.V., Chubarov D.L. An information system for acquisition, processing and access to satellite data and its applications in environmental monitoring // Computational Technologies. 2015. Vol. 20. No. 5. P. 157-174. (In Russ.)

[16] Wan Z., Dozier J. A generalized split-window algorithm for retrieving land-surface temperature from space // IEEE Trans. Geoscience and Remote Sensing. 1996. Vol. 34. No. 4. P. 892-905. 